\title{
Effectiveness of a decision aid for promoting colorectal cancer screening in Spain: a randomized trial
}

Lilisbeth Perestelo-Perez ${ }^{1,2,3,4^{*}}$ (D) Amado Rivero-Santana ${ }^{2,3,4}$, Alezandra Torres-Castaño ${ }^{4}$, Vanesa Ramos-Garcia ${ }^{4}$, Yolanda Alvarez-Perez ${ }^{4}$, Nerea Gonzalez-Hernandez ${ }^{2,5}$, Andrea Buron ${ }^{2,6}$, Michael Pignone ${ }^{7}$ and Pedro Serrano-Aguilar ${ }^{1,2,3,4}$

\begin{abstract}
Background: Colorectal cancer (CRC) screening has shown to reduce incidence and mortality rates, and therefore is widely recommended for people above 50 years-old. However, despite the implementation of population-based screening programs in several countries, uptake rates are still low. Decision aids (DAs) may help patients to make informed decisions about CRC screening.

Methods: We performed a randomized controlled trial to assess the effectiveness of a DA developed to promote CRC screening, with patients from two primary care centers in Spain who never had underwent CRC screening. Contrary to center $\mathrm{B}(n=24)$, Center $\mathrm{A}(n=83)$ attended patients from an area where the population-based screening program was not implemented at that moment. Outcome measures were decisional conflict, knowledge of the disease and available screening options, intention to uptake the test, and concordance between patients' goals/concerns and intention.

Results: In center A, there were significant differences favoring the DA in decisional conflict $(p<0.001)$ and knowledge $(p<0.001)$. The absolute differences favoring DA group in intention to undergo fecal occult blood test $(10.5 \%)$ and colonoscopy (13.7\%) were significant only before correction for attenuation. In center B the differences were significant only for knowledge $(p<0.001)$. Patients' goals and concerns regarding the screening did not significantly predict their intention, and therefore we could not calculate a measure of concordance between the two constructs.

Conclusions: A DA improved the decisional process of participants who had never been invited to participate in the Spanish public CRC screening program, replicating previous results in this field. Future research is needed to identify subgroups that could benefit more from these interventions.
\end{abstract}

Trial registration: International Standard Registered Clinical/social Study Number: ISRCTN98108615 (Retrospectively registered on 27 December 2018).

Keywords: Colorectal cancer screening, Decision aid, Patient involvement, Primary care, Randomized controlled trial, Shared decision-making, Spain

\footnotetext{
* Correspondence: lilisbethp@gmail.com

${ }^{1}$ Evaluation Unit of the Canary Islands Health Service (SESCS), s/n. 38109. El

Rosario. S/C de Tenerife, Tenerife, Spain

${ }^{2}$ Health Services Research on Chronic Patients Network (REDISSEC), Tenerife, Spain

Full list of author information is available at the end of the article
}

(c) The Author(s). 2019 Open Access This article is distributed under the terms of the Creative Commons Attribution 4.0 International License (http://creativecommons.org/licenses/by/4.0/), which permits unrestricted use, distribution, and reproduction in any medium, provided you give appropriate credit to the original author(s) and the source, provide a link to the Creative Commons license, and indicate if changes were made. The Creative Commons Public Domain Dedication waiver (http://creativecommons.org/publicdomain/zero/1.0/) applies to the data made available in this article, unless otherwise stated. 


\section{Background}

Colorectal cancer (CRC) is the third most common type of cancer in the world and one of the main causes of death by cancer, showing a wide geographical variation in incidence and mortality [1]. In western countries, these rates have declined from several decades ago due to the introduction of screening techniques (e.g., fecal occult blood test -FOBT-, colonoscopy, sigmoidoscopy), and the improvement in treatment [2-4]. CRC screening is therefore recommended for people above 50-years old, and population programs have been implemented in several countries at a national or regional level, however screening rates are still low [5-7]. Research has shown that screening uptake is significantly influenced by a wide range of sociodemographic, clinical, psychosocial, lifestyle and health system-related variables [8-11].

Proposed interventions to increase and improve recruitment for CRC screening have included reminders by health professionals, informational material in different formats (printed, videos, interactive computer programs), mailed FOBT kits, group education, counseling or provider or practice-directed interventions [12-14]. One of these practice-based interventions is the application of decision aids (DA). These tools include explanations of the available treatment or screening/diagnostic procedures, evidence-based quantitative information about their benefits and risks, and promote implicit or explicit clarification of patients' preferences about testing and its potential consequences [15, 16].

DAs have shown to improve patients' decisional process (e.g., knowledge of the disease and treatments, risk perceptions, decisional conflict, congruence between preferences and choices) in many physical and mental health conditions [17]. In the field of CRC, Volk et al. [18] recently published a systematic review and meta-analysis on the effectiveness of DAs. Pooled results showed that, compared to no-intervention, they significantly increased participants' knowledge, and screening intention and uptake, but when control groups were given general CRC screening information, only the difference in knowledge was significant.

In Spain, public population-based CRC screening programs have been heterogeneously implemented across and within its 17 autonomous regions, since the first initiative launched in Catalonia in 2000 [19]. Programs follow the European Guidelines, are entirely free of charge and biennially invite men and women aged 50 to 69 years to a FOBT test; colonoscopy as a diagnostic test is offered to those FOBT positive. Although screening rates have progressively increased through the successive rounds of the program, reaching about $40 \%$ of eligible population, they still are below the optimal recommended value or standards [20].

In this context, the aim of this study is to assess the effectiveness of a DA on the basic decisional processes (knowledge, decisional conflict, intention) about CRC screening of Spanish primary care patients eligible for the procedure. Secondarily, since in our region (Canary Islands) the public screening program has been implemented only in some areas, we wanted to assess the effect of the DA in participants who previously had been invited (and refused) to be screened compared to those who had never been invited.

\section{Methods}

We performed a randomized controlled trial (RCT) to assess the effectiveness of a web-based DA developed to promote informed decisions about CRC screening. Inclusion criteria were: age 50-69 years-old, having no CRC history or current symptoms, no family history of CRC, and no previous CRC screening. Two primary care centers in Tenerife (Canary Islands, Spain) participated in the study, carried out during 2016. One of them (hereafter, center A) attends patients in an area where the public CRC screening program was not implemented at that moment, although it was expected to be accessible in the next years. The other (center B) is in an area where the screening program have been running since 2009, and therefore its patients between 50 and 69 year$\mathrm{s}$-old had received invitations and reminders in the past to undergo the screening (but not specific information about the procedure). Collaborating physicians in both centers assessed the eligibility of their consecutive patients, and invited those eligible to be contacted by telephone by a member of our team, who explained the study in more detail and established an appointment in their primary care center.

Computer-based simple randomization was performed by a statistician not involved in the study, and the researcher who recruited participants and established an appointment by phone was blinded to allocation (we used a centralized off-site computer allocation process). All participants were received in a room of their primary care center by other researcher, who had the allocation list; all participants were assigned to the group in which they had been randomized. Intervention participants signed informed consent and reviewed the DA in the computer; the researcher was sitting beside them and briefly explained them the functioning of the DA and gave support in navigation when necessary. After that, participants filled the questionnaires assessing the outcome variables, in the same web-based interface, with no mediation of the researcher. Control participants only signed informed consent and completed the questionnaires, in a different interface of the web site. Therefore, all measures were assessed only once (after reviewing the DA in the intervention group), except knowledge in the DA group, which was assessed both before and after the DA application. 


\section{Decision aid}

The DA was a Spanish translation and adaptation of the one developed by Pignone et al. [21]. The adaptation process was performed with the support of an advisory group of health professionals related to CRC care. We carried out four focus groups with professionals and citizens eligible for screening (who had undergone the procedure or not), before and during the adaptation process. The final DA is presented in a web format that presents written information based on scientific evidence about CRC (available in: www.pydesalud.com/toma-dedecisiones-en-cancer-colorrectal/). It is organized in three sections; the first one explains the usefulness of DAs and a brief summary of their content. The second section explains CRC causes, symptoms and available treatments. Third, information on FOBT and colonoscopy is presented, including quantitative data about incidence and mortality risk reduction, as well as potential adverse effects. Finally, a summary table is presented with the two tests and their characteristics (i.e., description, preparation, recovery, frequency, need for additional tests, incidence and mortality risk reduction, adverse effects) compared to not being screened. Outcomes variables are then assessed in the same interface. Once the questionnaires have been completed, a summary document including the content explored, together with the answers given by the patients is automatically generated and available for them, in a printed format or via e-mail.

\section{Measures}

The primary outcome measure was decisional conflict, defined as uncertainty about the course of action to take when choosing among several medical procedures [21]. It was measured with the Spanish version of the Decisional Conflict Scale (DCS) [22, 23]. It includes 16 items and 5 subscales (with 3 items each, except the latter, with 4): feeling informed, having clear values about benefits and risks, support to take the decision, uncertainty, and perceived effectiveness of the decision. Items are scored from 0 (strongly agree) to 4 points (strongly disagree), with higher scores indicating higher decisional conflict. Scores on the total scale and subscales are transformed to a 0-100 scale. In two previous trials with Spanish patients diagnosed with type-2 diabetes and depression, respectively, we observed high internal consistency values (Cronbach alpha of 0.90 and 0.88 ) [24, 25]. We calculated that, assuming equal variances in the intervention and control groups, 126 participants would be needed to detect a moderate effect size (standardized mean difference $=0.5$ ), with a confidence level of $95 \%$ and a power of $80 \%$.

\section{Secondary outcomes}

Knowledge of colorectal cancer and screening options was assessed using a measure based on preliminary studies testing a Spanish-Language CRC screening decision aid in Latinos with limited English proficiency [26]. It includes 12 items with response format of "true/false/I don't know". The percentage of correct responses represents the knowledge score. The content of all items was explained in the DA.

We could not assess actual screening uptake in center B, and participants of center A did not have access to the public screening program and therefore could only undergo screening by means of private services, but this was considered improbable given the out of pocket costs. Therefore, we instead used intention to be screened as a proxy, which has shown to be a good predictor of CRC screening uptake $[27,28]$. Patients were asked two questions about their intention to undergo FOBT and colonoscopy, respectively (yes/no). Finally, we assessed the attributed importance for eight characteristics of screening when making a decision about it (goals/concerns), rating them from 1 (not important at all) to 5 (extremely important).

\section{Statistical analyses}

We performed one $2 \times 2$ analysis of variance (ANOVA) with each of the continuous outcomes (DCS and its subscales, knowledge) as dependent variable, and the intervention group (DA vs. control) and center (A/B) as independent variables. The change in knowledge in the DA group was analyzed by means of paired t-test. To assess differences between the DA and control groups in the intention to undergo FOBT and/or colonoscopy, respectively, we performed $\chi^{2}$ analyses for the whole sample and separately by center; since several of these analyses yielded expected frequencies $<5$ in the "no screening" cells, we also report the results corrected for continuity (Yates' correction).

The concordance between patients' goals/concerns about the screening procedure and their intention to be screened was calculated as proposed by Sepucha et al. [29] for operationalizing concordant decisions. First, univariate logistic regressions were performed with intention as dependent variable and each of the goals/ concerns about the screening procedure rated by patients as predictor. Those that showed a significant association were introduced together in a multiple logistic regression analysis, again with the intention as dependent variable. After excluding those that were no longer significant, the final model is used to calculate each subject's predicted probability of stating an intention to be (probability $\geq 0.5)$ or not to be $(<0.5)$ screened. Finally, participants were classified as concordant if their predicted probability coincided with their stated intention, and vice versa. Differences 


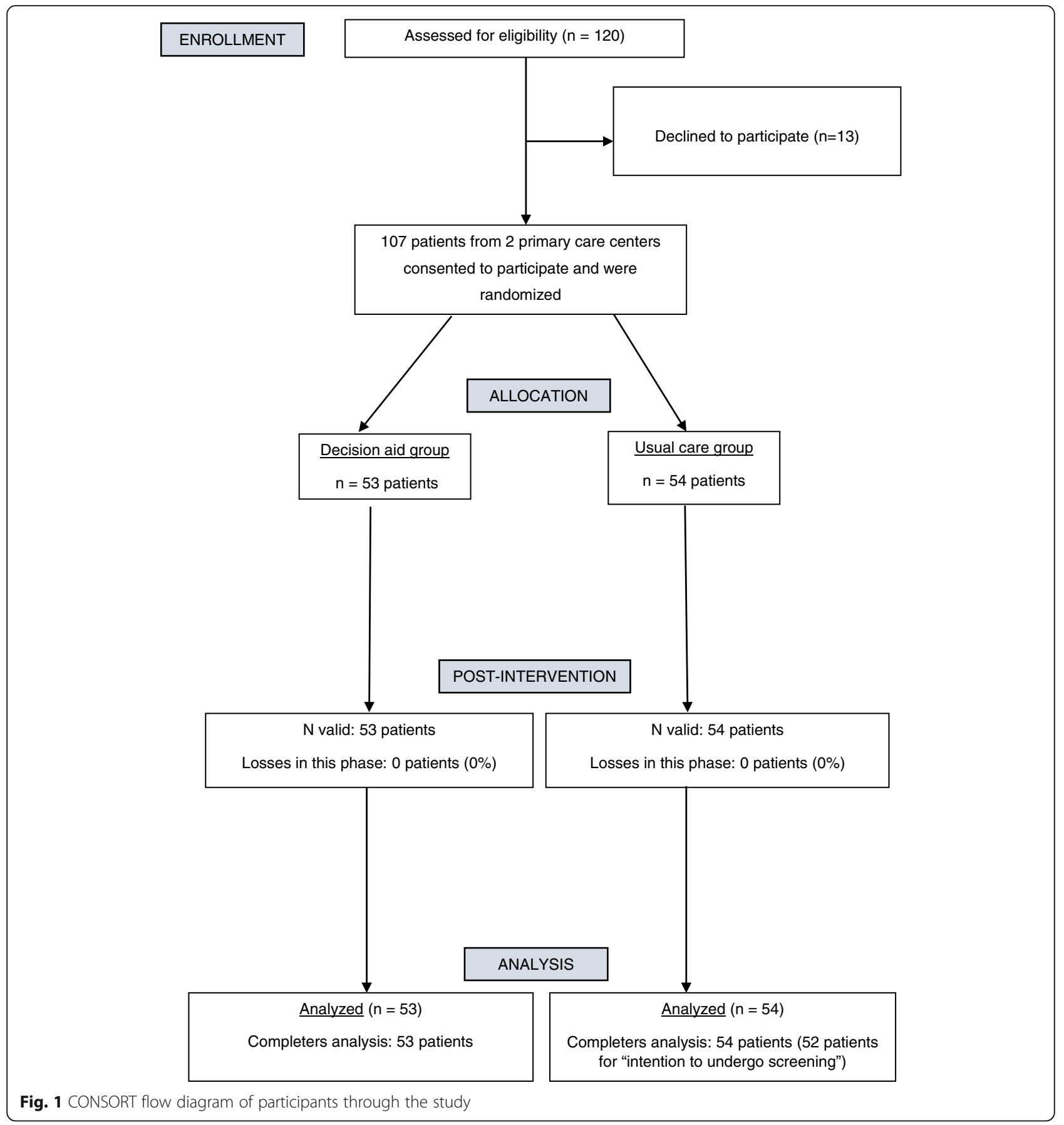

between DA and control groups in the rate of patients with concordant intentions was calculated by means of a $X^{2}$ test.

\section{Results}

Figure 1 shows the participants' flow chart and Table 1 their baseline characteristics. One hundred and twenty patients were informed about the study by the recruiter researcher, from whom 13 decline participation. Therefore, 107 participants were included, 83 from center A and 24 from center $\mathrm{B}$, and 53 and 54 patients were randomized to intervention (DA) and control groups, respectively. Mean age was 58.1 years-old, $57.9 \%$ were female and a $45.7 \%$ had completed secondary education. Patients from center A were significantly older than those from center B (mean of 59 vs. 55 years, respectively, $p=0.004)$ and included fewer women ( $52 \%$ vs. $79 \%$, $p=0.017$ ).

Table 2 shows the results of the different ANOVA performed for each of the continuous outcomes measures. 
Table 1 Baseline participants' characteristics

\begin{tabular}{lll}
\hline & DA group $(n=53)$ & Control group $(n=54)$ \\
\hline Age & $57.9(5.93)$ & $58.4(6.30)$ \\
Female & $33(62.3)$ & $29(53.7)$ \\
Education & & \\
$\quad$ No primary studies & $7(13.2)$ & $12(22.6)$ \\
$\quad$ Primary studies & $17(32.1)$ & $21(39.6)$ \\
$\quad$ Secondary studies & $21(39.6)$ & $15(28.3)$ \\
$\quad$ Universitary studies & $8(15.1)$ & $5(9.4)$ \\
Center A/B & $43 / 10(81 \% / 19 \%)$ & $40 / 14(74 \% / 26 \%)$ \\
\hline
\end{tabular}

The effect of center was significant only for the "informed" subscale, with patients from center B showing significantly less conflict $(p<0.001)$.

Regarding the effect of the intervention on decisional conflict, the interaction term was significant for the total score and three subscales (informed, values and uncertainty); post-hoc analyses showed that the DA only was effective in center A $(p<0.001)$. For the other two subscales there were not significant main or interaction effects, but when analyzed separately in center $\mathrm{A}$, t-tests yielded $p$-values of 0.003 (effectiveness) and 0.05 (support) favoring the DA. Differences ranged from 7.2 (support) to 62 points (informed).

Knowledge in the control group was not significantly different from pre-intervention scores in the DA group $(p=0.714)$, which after the intervention improved 16.6 points on average $(p<0.001)$. ANOVA yielded a significant main effect of the DA on knowledge (mean difference: $17.8 \%, p<0.001)$.

In the whole sample, most participants stated an intention to undergo FOBT (92.4\%) or colonoscopy (89.5\%). In center $\mathrm{A}$, the differences favoring the DA (FOBT: $100 \%$ vs. $89.5 \%$; Colonoscopy: $95.3 \%$ vs. $81.6 \%$ ) were significant for both procedures in the uncorrected analysis, but not when Yates' correction was applied
(Table 3). In center B, none of the analyses yielded significant results.

Table 4 shows the results obtained for each of the goals/ concern evaluated. Reducing both the probability of developing colorectal cancer (78\% of patients scoring 5 in a 15 scale) and dying by its cause (91\%) were rated by participants as the most important issues when deciding about CRC screening, followed by the risk of complications (70\%). Univariate associations between the importance attributed to each goal/concern and the intention to get screened were assessed by means of logistic regression and no significant results were observed. Including center as covariate or using non-parametric analyses (MannWhitney's U, Kolmogorov-Smirnov's test) did not change the results; therefore, a measure of concordance between goals/concerns and intention to be screened could not be constructed.

\section{Discussion}

This study aimed to assess the effectiveness of a DA for CRC screening on decisional conflict and knowledge of targeted Spanish participants who had never been screened, recruited in primary care services. We also evaluated the participants' intention to undergo the screening procedure. In addition, we included a small subsample of participants (center B) who had previously been invited (and refused) to be screened in the public program.

In center $\mathrm{A}$, results confirmed the beneficial effect of the DAs on the patients' decisional process found in previous studies in CRC [18] and other diseases [17]. Intervention group showed significantly higher knowledge (pre-post difference of 17 points) and lower decisional conflict than control participants, with a strong effect in the DCS Informed subscale (between-group difference of 62 points). Control participants showed an acceptable level of knowledge (60\% of correct responses), and nonetheless they expressed a high level of feeling uninformed. This result is in line with the relatively low correlation

Table 2 Effect of the intervention on knowledge and decisional conflict ${ }^{a}$

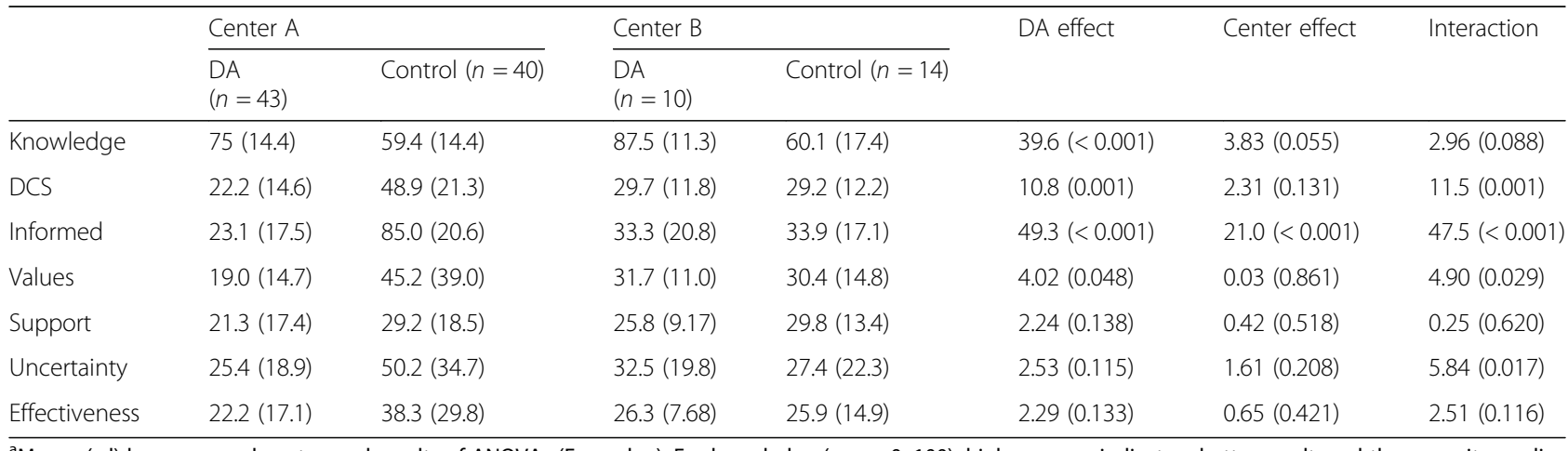

${ }^{a}$ Means (sd) by group and center, and results of ANOVAs ( $F$, p-value). For knowledge (range 0-100), higher scores indicate a better result, and the opposite applies for the decisional conflict scale (DCS) and its subscales (range 0-100). DA decision aid 
Table 3 Intention to undergo colorectal cancer screening

\begin{tabular}{|c|c|c|c|c|c|c|c|c|}
\hline \multirow[t]{3}{*}{ Intention } & \multicolumn{4}{|l|}{ FOBT } & \multicolumn{4}{|c|}{ Colonoscopy } \\
\hline & \multicolumn{2}{|c|}{ Center $\mathrm{A}\left(n=81^{*}\right)$} & \multicolumn{2}{|c|}{ Center B $(n=24)$} & \multicolumn{2}{|c|}{ Center $\mathrm{A}\left(n=81^{*}\right)$} & \multicolumn{2}{|c|}{ Center B $(n=24)$} \\
\hline & DA & Control & DA & Control & DA & Control & DA & Control \\
\hline Yes & $43(100 \%)$ & $34(89.5 \%)$ & $9(90 \%)$ & $11(78.6 \%)$ & 41 (95.3\%) & $31(81.6 \%)$ & $9(90 \%)$ & $13(92.9 \%)$ \\
\hline No & $0(0 \%)$ & $4(10.5 \%)$ & $1(10 \%)$ & $3(21.4 \%)$ & $2(4.7 \%)$ & 7 (18.4\%) & $1(10 \%)$ & $1(7.1 \%)$ \\
\hline$x^{2}$ (p-value) & \multicolumn{2}{|l|}{$4.76(0.029)$} & \multicolumn{2}{|c|}{$0.55(0.459)$} & \multicolumn{2}{|l|}{$3.87(0.049)$} & \multicolumn{2}{|c|}{$0.06(0.803)$} \\
\hline$x^{2}$ corrected for continuity & \multicolumn{2}{|l|}{$2.78(0.095)$} & \multicolumn{2}{|c|}{$0.34(0.853)$} & \multicolumn{2}{|l|}{$2.60(0.107)$} & \multicolumn{2}{|c|}{$0.00(1.000)$} \\
\hline
\end{tabular}

*Two missing values in the control group; FOBT fecal occult blood test, DA decision aid

between objective and subjective knowledge usually observed in previous research [30-32] $(r=0.35$ in this study), and highlights the need of educating about health topics not only to empower citizens with poor knowledge about these issues, but also to improve the subjective perception of been informed in those who already have a correct level of knowledge.

In center $\mathrm{B}$, the DA also significantly improved participants' knowledge, but had no effect on decisional conflict. Although the statistical power of the analysis was very low due to the small sample size, differences were minimal for the DCS total score and its subscales. A possible floor effect could be present, since the control group obtained relatively low scores (29 points in the total score). The effect of center was significant only for the subscale informed, with less conflict in center B. This could be reflecting the effect of the public program's invitations and reminders provided to these participants in the previous years, although this must be interpreted cautiously due the small sample size and the differences observed between centers in age and gender composition.

The percentage of participants who stated an intention to undergo screening was very high in the whole sample. Control group obtained a rate around $85 \%$, a value markedly greater than the observed in previous trials with control groups without intervention [33, 34], or even in those in which control participants were given general information about CRC [35-37]. Although intention significantly predicts screening uptake $[26,27]$, this seems to be an "inflated" result since screening rates in our region are around 40\% [20]. A possible explanation is that we used a yes/no response format (whether the patient had intention to be screened or not) but not the "intensity" of intention (usually assessed with a Likert scale [3739]), nor did we make explicit a time frame in which the decision had to be made. This could make it to seem more "hypothetical" for participants (and maybe more prone to desirability bias), and lead those in a more contemplative stage of decision making, in terms of the Transtheoretical Model of behavior change [40], to answer affirmatively. Performing the study physically in a health context (primary care centers) could also increase this desirability bias. In center $A$, the effect of the intervention was significant only before applying correction for continuity; nonetheless, the study was underpowered to detect the between-group difference estimated in the meta-analysis of Volk et al. [18]: $66 \%$ in the DA groups versus $45 \%$ in control groups with no intervention (168 participants would have been needed, with a $95 \%$ confidence level, to obtain a statistical power of $80 \%$ ), and therefore we cannot draw definitive conclusions about the effect of the DA on this measure. Finally, we did not find any significant associations between goals/ concerns and intention, a result that could be influenced by the low variability observed for both measures.

There are several limitations in this study, beyond the absence of screening uptake assessment. We did not

Table 4 Participants' goals and concerns about the screening procedure. Values are percentages, except for the right column (mean, sd)

\begin{tabular}{lllllll}
\hline & 1 (not important at all) & 2 & 3 & 4 & 5 (extremely important) & Mean (sd) \\
\hline Place in which the test is performed & 11.2 & 9.3 & 14.0 & 23.4 & 42.1 & $3.76(1.38)$ \\
Preparation process & 15.9 & 15.0 & 13.1 & 21.5 & 34.6 & $3.44(1.49)$ \\
Recovery process & 14.0 & 14.0 & 15.9 & 20.6 & 35.5 & $3.50(1.45)$ \\
Frequency of the test & 16.8 & 12.1 & 10.3 & 24.3 & 36.4 & $3.51(1.50)$ \\
Risk of complications & 2.8 & 0.9 & 3.7 & 22.4 & 70.1 & $4.56(0.85)$ \\
Possibility of needing additional tests & 8.4 & 9.3 & 9.3 & 31.8 & 41.1 & $3.88(1.28)$ \\
Reducing the probability of developing colorectal cancer & 0.9 & 0 & 0.9 & 20.6 & 77.6 & $4.74(0.57)$ \\
Reducing the probability of dying due to colorectal cancer & 0 & 0 & 0 & 9.3 & 90.7 & $4.91(0.29)$ \\
\hline
\end{tabular}


assess decisional conflict and intention at baseline, although randomization is expected to prevent biases in this sense. The absence of intervention in the control group may introduce a "novelty effect" in favor of the DA; to minimize as much as possible this potential bias we tried to offer the same experience (except for the application of the DA) to intervention and control participants: appointment in their primary care center, standardized instructions provided by the researcher, who did not mediated in participants' responses to questionnaires, which were delivered in the same way. Regarding external validity, a selection bias could be present since we recruited participants in primary care centers, who might not be completely representative of the population targeted for CRC screening. With these limitations in mind, the results confirmed the improvements of participants' knowledge observed in previous studies, and add evidence about the DAs effect on decisional conflict (a measure little used previously in the field of CRC screening), supporting their effectiveness to promote informed decisions about CRC screening. We also have provided preliminary evidence on the null effect of the DA on decisional conflict in participants who have been invited (and refused) to participate in a public screening program.

Beyond the positive effects of DAs effects on cognitive outcomes, however, their effect on intention and screening uptake are far from the desired rates from a public health perspective. The meta-analysis of Volk et al. [18] shows that the pooled rate in any DA group for screening intention/interest was $66 \%$ (95\% CI: $54-77 \%$ ) and only $33 \%$ (95\% CI: $22-46 \%$ ) for screening uptake. These results highlight the necessity to include a motivational component in interventions aimed to improved screening rates. On the other side, DAs outperform general information materials at improving knowledge, but not at increasing the rate of CRC screening, which raises questions about the quantity and specificity of information necessary or sufficient to decide to undergo the test.

\section{Conclusions}

Decision aids represent a useful resource to improve the quality of the decisional process about colorectal cancer screening, in terms of higher knowledge and less decisional conflict. However, preliminary evidence suggests that the effect on decisional conflict is not significant in people who have been previously invited to participate in a public screening program (although not specifically informed about the procedure). Future research should identify what subgroups could benefit more from DAs, as could occur with vulnerable populations [41, 42], and explore how values and motivational factors interact with knowledge and cognitive processes when making the decision about screening.

\section{Abbreviations}

ANOVA: Analysis of variance; CRC: Colorectal cancer; DA: Decision aid; DCS: Decisional Conflict Scale; FOBT: Fecal occult blood test; RCT: Randomized controlled trial

\begin{abstract}
Acknowledgements
We would like to acknowledge the essential role played in this research by the study participants, including healthcare professionals, as well as primary care patients, and the role of the staff in the practices in which this research was conducted.
\end{abstract}

\section{Funding}

This study was supported by the Spanish Ministry of Economy, Industry and Competitiveness (Carlos III Institute, Spain) (Grant number: PI12/00509). Funders have had no role in the study design, the collection, analysis, and interpretation of data, the writing of the article or the decision to submit it for publication.

\section{Availability of data and materials}

The datasets used and/or analyzed during the current study are available from the corresponding author on reasonable request. The decision aid is available in: http://www.pydesalud.com/toma-de-decisiones-en-cancer-colorrectal/.

\section{Authors' contributions}

LPP, ARS, NGH, AB, MP and PSA conceived the study and designed the trial. $L P P, N G H, A B$, and MP developed the intervention and supporting data. ARS, ATC and VRG provided statistical powering and an analysis strategy for the study, led data collection from the portal, then conducted data analysis. Both NGH and AB also assisted LPP on interpretation of findings. LPP, ATC, VRG, YAP, and PSA supervised the conduct of the trial and data collection. LPP and $A R$ designed the intervention interface, information security, and data retrieval strategy. ATC, VRG and YAP undertook recruitment of participants and data collection. LPP and ARS drafted the article, and all authors contributed substantially to its revision and approved final version. LPP take responsibility for the paper as a whole

\section{Ethics approval and consent to participate}

The Scientific and Ethics Committee of the University Hospital Nuestra Señora de la Candelaria (Tenerife, Spain) approved the study protocol (file number: 2013/21). The study was performed in accordance with Good Clinical Practice standards, applicable local regulatory requirements and the recommendations of the Declaration of Helsinki.

This was a web-based study and the informed consent was built into the intervention. It was included in the intervention slides just after the welcome. It was an electronic consent document where the participant was required to accept to proceed with the study. If he/she did not consent the system thanked them for their interest but did not let them proceed. Control participants signed informed consent in a different interface of the web site.

Consent for publication

Not applicable.

\section{Competing interests}

The authors declare that they have no competing interests.

\section{Publisher's Note}

Springer Nature remains neutral with regard to jurisdictional claims in published maps and institutional affiliations.

\section{Author details}

${ }^{1}$ Evaluation Unit of the Canary Islands Health Service (SESCS), s/n. 38109. El Rosario. S/C de Tenerife, Tenerife, Spain. ${ }^{2}$ Health Services Research on Chronic Patients Network (REDISSEC), Tenerife, Spain. ${ }^{3}$ Center for Biomedical Research of the Canary Islands (CIBICAN), Tenerife, Spain. ${ }^{4}$ Canary Islands Foundation of Health Research (FUNCANIS), Tenerife, Spain. ${ }^{5}$ Research Unit. Hospital Galdakao-Usansolo, Bilbao, Bizkaia, Spain. ${ }^{6}$ Epidemiology and Evaluation Unit. Hospital del Mar, Barcelona, Spain. ${ }^{7}$ Dell Medical School. University of Texas, Austin, TX, USA. 
Received: 11 July 2017 Accepted: 2 January 2019

\section{Published online: 10 January 2019}

\section{References}

1. GLOBOCAN. Colorectal Cancer: Estimated incidence, mortality and prevalence worldwide in 2012. International Agency for Research on Cancer. 2012. http://globocan.iarc.fr/Default.aspx.

2. Browse the SEER Cancer Statistics Review (CSR) 1975-2013. https://seer cancer.gov/archive/csr/1975_2013/browse_csr.php?sectionSEL=6\&pageSEL= sect_06_table.09.html. Accessed 13 Jun 2017.

3. Torre LA, Bray F, Siegel RL, Ferlay J, Lortet-Tieulent J, Jemal A. Global cancer statistics, 2012. CA Cancer J Clin. 2015;65:87-108. https://doi.org/10.3322/ caac.21262.

4. Ait Ouakrim D, Pizot C, Boniol M, Malvezzi M, Boniol M, Negri E, et al. Trends in colorectal cancer mortality in Europe: retrospective analysis of the WHO mortality database. BMJ. 2015;351:h4970. https://doi.org/10.1136/bmj.h4970.

5. Verma M, Sarfaty M, Brooks D, Wender RC. Population-based programs for increasing colorectal cancer screening in the United States. CA Cancer J Clin. 2015;65:496-510. https://doi.org/10.3322/caac.21295.

6. Cancer Screening in the European Union. Report on the implementation of the council recommendation on cancer Screening. 2017.

7. Schreuders EH, Ruco A, Rabeneck L, Schoen RE, Sung JJY, Young GP, et al. Colorectal cancer screening: a global overview of existing programmes. Gut. 2015;64:1637-49. https://doi.org/10.1136/gutjnl-2014-309086.

8. Beydoun HA, Beydoun MA. Predictors of colorectal cancer screening behaviors among average-risk older adults in the United States. Cancer Causes Control. 2008;19:339-59. https://doi.org/10.1007/s10552-007-9100-y.

9. Deding $U$, Henig AS, Salling A, Torp-Pedersen C, Bøggild H. Sociodemographic predictors of participation in colorectal cancer screening. Int J Color Dis. 2017;32(8):1117-24. https://doi.org/10.1007/ s00384-017-2832-6.

10. Pornet C, Denis B, Perrin P, Gendre I, Launoy G. Predictors of adherence to repeat fecal occult blood test in a population-based colorectal cancer screening program. Br J Cancer. 2014;111:2152-5. https://doi.org/10.1038/ bjc.2014.507.

11. Gale CR, Deary IJ, Wardle J, Zaninotto P, Batty GD. Cognitive ability and personality as predictors of participation in a national colorectal cancer screening programme: the English longitudinal study of ageing. J Epidemiol Community Health. 2015;69:530-5. https://doi.org/10.1136/ jech-2014-204888.

12. Brouwers MC, De Vito C, Bahirathan L, Carol A, Carroll JC, Cotterchio M, et al. Effective interventions to facilitate the uptake of breast, cervical and colorectal cancer screening: an implementation guideline. Implement Sci. 2011:6:112. https://doi.org/10.1186/1748-5908-6-112.

13. Sabatino SA, Lawrence B, Elder R, Mercer SL, Wilson KM, DeVinney B, et al. Effectiveness of interventions to increase screening for breast, cervical, and Colorectal cancers. Am J Prev Med. 2012;43:97-118. https://doi.org/10.1016/ j.amepre.2012.04.009.

14. Rawl SM, Menon U, Burness A, Breslau ES. Interventions to promote colorectal cancer screening: an integrative review. Nurs Outlook. 2012;60: 172-81.e13. https://doi.org/10.1016/j.outlook.2011.11.003.

15. Elwyn G, O'Connor A, Stacey D, Volk R, Edwards A, Coulter A, et al. Developing a quality criteria framework for patient decision aids: online international Delphi consensus process. BMJ. 2006;333:417. https://doi.org/ 10.1136/bmj.38926.629329.AE.

16. Coulter A, Stilwell D, Kryworuchko J, Mullen P, Ng C, van der Weijden T. A systematic development process for patient decision aids. BMC Med Inform Decis Mak. 2013;13(Suppl 2):S2. https://doi.org/10.1186/1472-6947-13-S2-S2.

17. Stacey $D$, Légaré $F$, Lewis $K$, Barry MJ, Bennett $C L$, Eden $K B$, et al. Decision aids for people facing health treatment or screening decisions. Cochrane Database Syst Rev. 2017:4:CD001431.

18. Volk RJ, Linder SK, Lopez-Olivo MA, Kamath GR, Reuland DS, Saraykar SS, et al. Patient decision aids for Colorectal Cancer screening. Am J Prev Med. 2016;51:779-91. https://doi.org/10.1016/j.amepre.2016.06.022.

19. Binefa G, Garcia M, Milá N, Fernández E, Rodríguez-Moranta F, Gonzalo N, et al. Colorectal Cancer screening Programme in Spain: results of key performance indicators after five rounds (2000-2012). Sci Rep. 2016;6:19532. https://doi.org/10.1038/srep19532.

20. Portillo-Villares I, Arana-Arri E, Idigoras-Rubio I, Espinás-Piñol JA, PérezRiquelme $F$, de la Vega Prieto $M$, et al. Lesions detected in six Spanish Colorectal Cancer screening population based Programmes. CRIBEA Project
Spain. Rev Esp Salud Publica. 2017;91:e201701021 http://www.ncbi.nlm.nih. gov/pubmed/28218734.

21. Pignone M, Winquist A, Schild LA, Lewis C, Scott T, Hawley J, et al. Effectiveness of a patient and practice-level colorectal cancer screening intervention in health plan members. Cancer. 2011;117:3352-62. https://doi. org/10.1002/cncr.25924.

22. O'Connor AM. Validation of a decisional conflict scale. Med Decis Mak. 1995; 15:25-30. https://doi.org/10.1177/0272989X9501500105.

23. Urrutia M, Campos S, O'Connor A. Validación de una versión en español de la Escala de Conflicto Decisional. Rev Med Chil. 2008;136. https://doi.org/10. 4067/S0034-98872008001100010.

24. Perestelo-Pérez L, Rivero-Santana A, Boronat M, Sánchez-Afonso JA, PérezRamos J, Montori VM, et al. Effect of the statin choice encounter decision aid in Spanish patients with type 2 diabetes: a randomized trial. Patient Educ Couns. 2016:99:295-9. https://doi.org/10.1016/j.pec.2015.08.032.

25. Perestelo-Perez L, Rivero-Santana A, Sanchez-Afonso JA, Perez-Ramos J, Castellano-Fuentes $\mathrm{CL}$, Sepucha $\mathrm{K}$, et al. Effectiveness of a decision aid for patients with depression: a randomized controlled trial. Health Expect. 2017. https://doi.org/10.1111/hex.12553.

26. Reuland DS, Ko LK, Fernández A, Braswell LC, Pignone M. Testing a Spanishlanguage colorectal cancer screening decision aid in Latinos with limited English proficiency: results from a pre-post trial and four month follow-up survey. BMC Med Inform Decis Mak. 2012;12:53. https://doi.org/10.1186/ 1472-6947-12-53.

27. Schroy PC, Emmons KM, Peters E, Glick JT, Robinson PA, Lydotes MA, et al. Aid-assisted decision making and Colorectal Cancer screening. Am J Prev Med. 2012;43:573-83. https://doi.org/10.1016/j.amepre.2012.08.018.

28. Kim J, Whitney A, Hayter S, Lewis C, Campbell M, Sutherland L, et al. Development and initial testing of a computer-based patient decision aid to promote colorectal cancer screening for primary care practice. BMC Med Inform Decis Mak. 2005;5:36. https://doi.org/10.1186/1472-6947-5-36.

29. Sepucha KR, Feibelmann S, Cosenza C, Levin CA, Pignone M. Development and evaluation of a new survey instrument to measure the quality of colorectal cancer screening decisions. BMC Med Inform Decis Mak. 2014;14: 72. https://doi.org/10.1186/1472-6947-14-72.

30. Man-Son-Hing M, Laupacis A. A patient decision aid regarding antithrombotic therapy for stroke prevention in atrial fibrillation: a randomized controlled trial. JAMA. 1999;282:737-43. https://doi.org/10.1001/ jama.282.8.737.

31. O'Connor AM, Tugwell $P$, Wells GA, Elmslie T, Jolly E, Hollingworth $G$, et al. Randomized trial of a portable, self-administered decision aid for postmenopausal women considering long-term preventive hormone therapy. Med Decis Mak. 1998;18:295-303. https://doi.org/10.1177/ 0272989X9801800307

32. Laupacis A, O'Connor AM, Drake ER, Rubens FD, Robblee JA, Grant FC, et al. A decision aid for autologous pre-donation in cardiac surgery?A randomized trial. Patient Educ Couns. 2006;61:458-66. https://doi.org/10. 1016/j.pec.2005.05.014

33. Miller DP, Spangler JG, Case LD, Goff DC, Singh S, Pignone MP. Effectiveness of a web-based Colorectal Cancer screening patient decision aid. Am J Prev Med. 2011:40:608-15. https://doi.org/10.1016/j.amepre.2011.02.019.

34. Pignone $M$, Harris R, Kinsinger L. Videotape-based decision aid for colon cancer screening. A randomized, controlled trial. Ann Intern Med. 2000;133: $761-9$.

35. Smith SK, Trevena L, Simpson JM, Barratt A, Nutbeam D, KJ MC. A decision aid to support informed choices about bowel cancer screening among adults with low education: randomised controlled trial. BMJ. 2010;341:c5370. https://doi.org/10.1136/bmj.c5370.

36. Steckelberg A, Hulfenhaus C, Haastert B, Muhlhauser I. Effect of evidence based risk information on "informed choice" in colorectal cancer screening: randomised controlled trial. BMJ. 2011;342:d3193. https://doi.org/10.1136/ bmj.d3193.

37. Wolf AM, Schorling JB. Does informed consent alter elderly patients' preferences for colorectal cancer screening? Results of a randomized trial. J Gen Intern Med. 2000;15:24-30. https://doi.org/10.1046/j.1525-1497.2000.01079.x.

38. Griffith JM, Fichter M, Fowler FJ, Lewis C, Pignone MP. Should a colon cancer screening decision aid include the option of no testing? A comparative trial of two decision aids. BMC Med Inform Decis Mak. 2008;8: 10. https://doi.org/10.1186/1472-6947-8-10.

39. Schroy PC, Duhovic E, Chen CA, Heeren TC, Lopez W, Apodaca DL, et al. Risk stratification and shared decision making for Colorectal Cancer 
screening. Med Decis Mak. 2016;36:526-35. https://doi.org/10.1177/ $0272989 \times 15625622$.

40. Prochaska JO, Redding CA, Evers K. The Transtheoretical model and stages of change. In: Glanz K, Rimer BK, Lewis FM, editors. Health behavior and health education: theory, research, and practice. 3rd ed. San Francisco: Jossey-Bass, Inc.; 2002.

41. Durand M-A, Carpenter L, Dolan H, Bravo P, Mann M, Bunn F, et al. Do interventions designed to support shared decision-making reduce health inequalities? A systematic review and meta-analysis. PLoS One. 2014;9: e94670. https://doi.org/10.1371/journal.pone.0094670.

42. Gentles SJ, Stacey D, Bennett C, Alshurafa M, Walter SD. Factors explaining the heterogeneity of effects of patient decision aids on knowledge of outcome probabilities: a systematic review sub-analysis. Syst Rev. 2013;2:95. https://doi.org/10.1186/2046-4053-2-95.

Ready to submit your research? Choose BMC and benefit from:

- fast, convenient online submission

- thorough peer review by experienced researchers in your field

- rapid publication on acceptance

- support for research data, including large and complex data types

- gold Open Access which fosters wider collaboration and increased citations

- maximum visibility for your research: over $100 \mathrm{M}$ website views per year

At BMC, research is always in progress.

Learn more biomedcentral.com/submissions 